\title{
INFLUÊNCIA DA POLINIZAÇÃO COM VARIEDADES DE LARANJA-DOCE SOBRE O NÚMERO DE SEMENTES DE TANGELO NOVA ${ }^{1}$
}

\author{
ALINE ENILA FERRARO², ROSE MARY PIO ${ }^{3}$, FERNANDO ALVES DE AZEVEDO ${ }^{4}$
}

\begin{abstract}
RESUMO - O objetivo deste trabalho foi estudar a influência da polinização sobre o número de sementes de tangelo Nova. O experimento foi conduzido no Pólo de Desenvolvimento Tecnológico dos Agronegócios do Sudoeste Paulista/DDD, em Capão Bonito (SP), na safra $2004-2005$. Flores de plantas de tangelo Nova, com nove anos, foram tratadas durante o florescimento em 2004, como segue: 1. Polinização com laranja Valência; 2. Polinização com laranja Natal; 3. Polinização com laranja Pêra; 4. Isolamento de flores emasculadas; 5. Isolamento de flores completas, e 6. Testemunha (flor livre). Em maio de 2005, os frutos foram colhidos. Embora não tenha existido diferença estatística entre os resultados, em valores absolutos, a maior porcentagem de frutos colhidos foi observada no tratamento com laranja Pêra (42\%). Nos tratamentos 4 e 5 não houve frutos colhidos, o que sugere que este tangelo não desenvolveu frutos partenocárpicos nas condições deste estudo. Nos tratamentos com polinização cruzada, observaram-se entre 20 e 23 sementes nos frutos, o que mostra a influência da polinização nas características dos frutos. Não se observaram diferenças significativas nas qualidades do fruto.
\end{abstract}

Termos de indexação: tangerina, citros, polinização cruzada.

\section{POLLINATION INFLUENCE OF SWEET ORANGE VARIETIES ON 'NOVA TANGELO'SEEDS PRODUCTION}

\begin{abstract}
The objective of this work was to study the pollination influence on Nova tangelo seed production. The experiment was carried out in the Pólo de Desenvolvimento Tecnológico dos Agronegócios do Sudoeste Paulista/DDD, Capão Bonito, SP, Brazil, during 2004/2005 crop. Nine years old flowers of Nova tangelo plants were treated as follows: 1 . Valencia sweet orange pollination; 2 . Natal sweet orange pollination; 3. Pera sweet orange pollination; 4. emasculated flower isolation; 5. complete flower isolation and 6. Check (free flower). In May 2005, the fruits were harvested. The highest harvested fruits percentage was obtained in Pera sweet orange treatment (42\%). No fruits were obtained in treatments 4 and 5, suggesting that this tangelo did not develop partenocarpic fruits in this study conditions. In cross-pollination treatments was observed between 20 and 23 seeds in the fruits, which shows an evident pollination influence on fruit characteristic. No significant differences were noticed in fruit quality.
\end{abstract}

Index terms: mandarin, citrus, cross-pollination.

\section{INTRODUÇÃO}

Os cítricos são os frutos mais produzidos no mundo. Nesse grupo se incluem as laranjas (58\%), as tangerinas e híbridos $(21 \%)$ limões e limas (11\%) e grapefruit ou pomelos (4\%), entre outros. Brasil, Estados Unidos e China são os países responsáveis por mais de $46 \%$ da produção mundial de citros e, juntos com México e Espanha, formam os cinco maiores produtores do mundo (FAO, 2005).

No Brasil, a produção de citros é constituída basicamente de laranjas $(89 \%)$. As tangerinas representam apenas $6 \%$ do total produzido (FAO, 2005), sendo São Paulo, com 25 mil hectares plantados, o principal Estado produtor (com aproximadamente 53\% da produção), seguido por Rio Grande do Sul (15\%) e Paraná (13\%) (IBGE, 2006). Em São Paulo, as variedades que mais se destacam são: Poncã (Citrus reticulata Blanco), e tangor Murcott (Citrus sinensis (L.) Osbeck x C. reticulata Blanco). As demais, Mexerica-do-Rio ( $C$. deliciosa Tenore) e principalmente a tangerina Cravo (Citrus reticulata Blanco) apresentam poucos plantios (Pio et al., 2005).

Segundo Gayet (1993), para o mercado internacional, as variedades de tangerina plantadas no Brasil não atendem ao padrão de aceitação para serem consumidas como fruta fresca. Este mercado valoriza muito as frutas sem sementes. O tangor Murcott, que é exportado, apresenta cerca de 20 sementes por fruto. Já Pio (2003) ressalta que, além de frutos sem sementes, o consumidor busca frutas de sabor diferente, tamanho, cor e formas atrativas, fáceis de descascar, com vida de prateleira maior e livre de resíduos químicos. Assim, tornam-se necessárias no País, pesquisas e produção de novas tangerinas e híbridos, no sentido de ingressar no comércio mundial e abastecer o mercado interno que se encontra em ampla expansão.
Além das seleções de clementinas, alguns híbridos têm-se mostrado com bom potencial em alguns países, como Espanha, Israel, Estados Unidos, Austrália e Japão. Um exemplo é o aumento no plantio de tangelo Nova em áreas de cultivo na Espanha e Israel. Na Flórida, este vem ganhando popularidade em detrimento ao tangelo Orlando (Saunt, 1990). No Brasil, em ensaios de competição entre variedades de tangerinas e híbridos em 15 localidades no Estado de São Paulo, o tangelo Nova foi uma variedade que se destacou na região do município de Capão Bonito. Esse destaque ocorreu por suas características organolépticas e de aparência, mostrando-se bastante promissor, além de apresentar boas perspectivas de exportação devido a sua produção ocorrer na entressafra do Hemisfério Norte.

Nos países que abastecem o mercado internacional de fruta fresca, há uma grande preocupação em se estudarem os efeitos de possíveis cruzamentos entre variedades, para que as características desejáveis, como o baixo número de sementes ou mesmo a ausência delas, não sejam alteradas. Esses estudos fornecem também importantes informações para o adequado planejamento por ocasião da instalação de novos pomares. O objetivo deste trabalho foi o de estudar as características do tangelo Nova, mediante polinização controlada com variedades comerciais, com ênfase para o número de sementes por fruto e manutenção de suas qualidades organolépticas.

\section{MATERIAL E MÉTODOS}

O experimento foi instalado em agosto de 2004, no município de Capão Bonito-SP, no Pólo de Desenvolvimento Tecnológico dos Agronegócios do Sudoeste Paulista/DDD, utilizando-se de seis plantas de tangelo Nova, com nove anos, enxertadas em tangerina

\footnotetext{
' (Trabalho 037-2006). Recebido: 03-04-2006. Aceito para publicação: 06-07-2006. Parte da dissertação da primeira autora defendida em 20 de abril de 2006, no curso de Pós-Graduação do Instituto Agronômico, Campinas-SP.

${ }^{2}$ Eng. Agr. MSc., Instituto Nacional de Colonização e Reforma Agrária/INCRA, Rua 08, Q 15, Cep 78.050-090. Cuibá-MT. E-mail: alineferraro@ gmail.com ${ }^{3}$ Bióloga, Dra., Centro APTA Citros "Sylvio Moreira" (IAC), Rodovia Anhanguera, KM 158, Caixa Postal 4, CEP 13490-970, Cordeirópolis-SP. Bolsista CNPq. E-mail: rose@centrodecitricultura.br.

${ }^{4}$ Eng. Agr. Dr., Centro APTA Citros "Sylvio Moreira" (IAC), Rodovia Anhanguera, KM 158, Caixa Postal 4, CEP 13490-970, Cordeirópolis-SP. E-mail: fernando@ centrodecitricultura.br.
} 
TABELA 1 - Porcentagem média de frutos fixados (PFF), colhidos (PFC) e número médio de sementes (NMS) por fruto de tangelo Nova originados a partir de polinização controlada (Capão Bonito, 2004).

\begin{tabular}{|c|c|c|c|}
\hline \multirow[b]{2}{*}{ Tratamentos } & \multicolumn{3}{|c|}{ Valores Médios * } \\
\hline & $\mathrm{PFF}^{1}$ & $\mathrm{PFC}^{2}$ & $\mathrm{NMS}^{3}$ \\
\hline 3. Polinização com laranja Pêra & $45 \mathrm{a}$ & $42 \mathrm{a}$ & $23,5 \mathrm{a}$ \\
\hline 1. Polinização com laranja Valência & $37 \mathrm{ab}$ & $33,5 \mathrm{a}$ & $20 \mathrm{a}$ \\
\hline 6. Testemunha & $31,5 \mathrm{ab}$ & $24,5 \mathrm{a}$ & $20,5 \mathrm{a}$ \\
\hline 2. Polinização com laranja Natal & $26 \mathrm{~b}$ & $22,5 \mathrm{a}$ & $23,5 \mathrm{a}$ \\
\hline 4. Isolamento de flor emasculada & $0 \mathrm{c}$ & $0 \mathrm{~b}$ & - \\
\hline 5. Isolamento de flor completa & $0 \mathrm{c}$ & $0 \mathrm{~b}$ & - \\
\hline Coeficiente de Variação & 13,07 & 19,16 & 8,45 \\
\hline
\end{tabular}

${ }^{1,2}$ Dados originais, para fins de análise, foram transformados em arco-seno " $\mathrm{x}$.

${ }^{3}$ Dados originais, para fins de análise, foram transformados em " $\mathrm{x}+0,5$.

* Médias seguidas de mesma letra na coluna não diferem entre si, ao nível de 5\% de significância, pelo teste de Tukey.

Cleópatra (Citrus reshni hort. ex. Tan.), plantadas em espaçamento $6 \times 4 \mathrm{~m}$. O delineamento adotado foi o de blocos inteiramente casualizados, com duas repetições. Os tratamentos propostos foram: 1. Polinização com laranja Valência; 2. Polinização com laranja Natal; 3. Polinização com laranja Pêra; 4. Isolamento de flores emasculadas; 5. Isolamento de flores completas, e 6. Testemunha (flor livre).

O início da experimentação no campo foi efetuado no Banco Ativo de Germoplasma de Citros, do Centro Avançado de Pesquisa Tecnológica do Agronegócio de Citros Sylvio Moreira/IAC, em Cordeirópolis - SP, onde se coletaram 100 botões florais fechados, grandes e jovens de cada variedade polinizadora, segundo Cameron \& Frost (1968). Estes foram mantidos em placas de Petri com papelfiltro (após a retirada de suas pétalas), e armazenadas em estufa à temperatura de $30^{\circ} \mathrm{C}$, por 24 horas. Após esse procedimento, as placas foram encaminhadas para o local de instalação do ensaio (Capão Bonito) para ser realizada a polinização nas plantas de tangelo Nova.

Para cada tratamento com polinização (tratamentos 1; 2 e 3), foram escolhidas 100 flores fechadas e com o tamanho denominado "cotonete", ao acaso, ao redor da planta (Bono et al., 1988; Bono et al., 1989). Essas flores foram emasculadas (retirada da parte masculina) com o auxílio de pinça, receberam o pólen coletado e foram marcadas com fitas de cores diferentes, correspondentes a cada tratamento (Socias, 1987). No tratamento 4, as 100 flores tiveram suas pétalas e estames retirados, ou seja, emasculadas, e foram marcadas e ensacadas. Já no tratamento 5 , as flores foram mantidas intactas (antes de se abrirem), marcadas com fita colorida e ensacadas; e no tratamento 6 , as flores foram apenas marcadas e deixadas livres para que ocorresse a polinização cruzada natural.

Seis meses após a instalação do experimento no campo, em fevereiro de 2005, foi realizada avaliação do número de frutos fixados e, em maio de 2005, foi realizada a colheita. Dos frutos colhidos, retirouse uma amostra de cinco por repetição, os quais foram destinados às análises físico-químicas realizadas no Laboratório de Qualidade e PósColheita do Centro Avançado de Pesquisa Tecnológica do Agronegócio de Citros Sylvio Moreira/IAC.

A determinação de massa dos frutos das amostras foi obtida em balança, com precisão de 5g. Os diâmetros longitudinal e equatorial dos frutos foram obtidos por leitura direta de cada amostra, com o auxílio de uma régua tipo calha, graduada em centímetros. O número de sementes foi obtido pela contagem direta de todos os frutos colhidos, calculando-se a média por repetição. O rendimento de suco foi determinado após esmagamento em extratora e calculado por meio da relação massa do suco/massa do fruto e expresso em porcentagem. O teor de sólidos solúveis foi determinado por leitura direta em refratômetro, corrigindo-se os dados pela temperatura e pela acidez do suco, e expresso em ${ }^{\circ}$ Brix. A acidez total foi obtida por titulação de $25 \mathrm{~mL}$ de suco, com uma solução padronizada de hidróxido de sódio a 0,3125 de normalidade e usando-se fenoftaleína como indicadora, e os resultados, expressos em porcentagem de acordo com Reed et al. (1986), e o ratio, pela relação direta Brix/acidez.

\section{RESULTADOS E DISCUSSÃO}

a) Porcentagem de frutos fixados e colhidos

Dos tratamentos que envolveram polinização cruzada com variedades comerciais das laranjeiras-doces Pêra, Valência e Natal, a polinização com pólen de Pêra resultou em maior fixação de frutos (45\%) do que a polinização com laranja Natal (26\%) (Tabela 1), embora os outros tratamentos não se diferenciem estatisticamente da testemunha. No tratamento 4, isolamento de flor emasculada, não houve fixação de frutos, sugerindo que, nas condições testadas, não houve o desenvolvimento de frutos partenocárpicos. O tratamento 5 também não propiciou fixação de frutos, comprovando a auto-incompatibilidade do tangelo Nova e a não-fixação de frutos partenocárpicos nas condições do experimento. Vale lembrar que, de acordo com Guardiola (1992), a capacidade de produzir frutos partenocárpicos pode variar fortemente com o clima e condições de crescimento, e que cultivares que têm sido relatadas como partenocárpicas fracas em alguns locais, em outros apresentam forte partenocarpia e rendimento sem qualquer tratamento para ajuste da frutificação.

No tratamento 6, a testemunha, não se teve controle das fontes de pólen, sendo que a polinização cruzada envolveu diversas variedades de laranjas e tangerinas presentes nas proximidades da área experimental.

Há relatos na literatura do incremento da fixação de frutos e, conseqüentemente, na produção do pomar, quando existe ação de agentes polinizadores na polinização cruzada (Departament of Agriculture - Western Australia, 2004). Porém essa condição não pôde ser confirmada neste experimento, já que não houve a fixação de frutos nos tratamentos que não envolveram a polinização cruzada (tratamentos 4 e 5).

Com relação aos frutos colhidos, a polinização com laranja Pêra, embora tenha resultado em maior porcentagem de frutos (42\%), não houve diferença estatística dos resultados (Tabela 1), o que pode ter ocorrido devido ao maior coeficiente de variação observado nesta variável.

b) Característica dos frutos - massa e diâmetros longitudinal (DL) e equatorial (DE)

Os valores médios de massa e diâmetros longitudinal e equatorial não apresentaram diferença estatística entre os tratamentos (Tabela 2). Considerando-se que não foi feito o desbaste de frutos na área e que se realizaram apenas os tratos rotineiros da cultura, os resultados foram bastante próximos dos verificados por Pio et al. (1993) no Brasil, ou seja, valores entre 149,31 a 207,81 g para massa dos frutos, DL entre 6,17 e 6,73 cm e DE entre 6,98 e 8,04 cm.

c) Análise do suco - rendimento, sólidos solúveis totais (SST), acidez total (AT) e ratio

Não houve diferenças significativas entre os tratamentos quanto às análises do suco (Tabela 3 ). Os valores obtidos para rendimento de suco foram próximos do descrito para a variedade no Brasil, ou seja, entre 40 a 55\% (Pio et al., 1993). Para SST, os valores encontrados ficaram pouco abaixo dos descritos por Pio et al. (1993), 
TABELA 2 - Características dos frutos de tangelo Nova originados a partir de polinização controlada (Capão Bonito, 2004).

\begin{tabular}{lccc}
\hline & \multicolumn{3}{c}{ Característica dos frutos * } \\
\cline { 2 - 4 } \multicolumn{1}{c}{ Tratamentos } & Massa $(\mathrm{g})$ & DL $(\mathrm{cm})$ & DE $(\mathrm{cm})$ \\
\hline 6. Testemunha & $214,5 \mathrm{a}$ & $6,40 \mathrm{a}$ & $7,95 \mathrm{a}$ \\
3. Polinização com laranja Pêra & $213,0 \mathrm{a}$ & $6,35 \mathrm{a}$ & $8,20 \mathrm{a}$ \\
1. Polinização com laranja Valência & $197,5 \mathrm{a}$ & $6,30 \mathrm{a}$ & $7,85 \mathrm{a}$ \\
2. Polinização com laranja Natal & $193,5 \mathrm{a}$ & $6,25 \mathrm{a}$ & $8,15 \mathrm{a}$ \\
\hline Coeficiente de Variação & 5,87 & 0,91 & 1,67 \\
\hline
\end{tabular}

* Médias seguidas de mesma letra na coluna não diferem entre si, ao nível de 5\% de significância, pelo teste de Tukey.

TABELA 3 - Análise qualitativa do suco dos frutos de tangelo Nova originados a partir de polinização controlada (Capão Bonito, 2004).

\begin{tabular}{lcccc}
\hline & \multicolumn{3}{c}{ Qualidade do suco * } \\
\cline { 2 - 5 } \multicolumn{1}{c}{ Tratamentos } & Rendimento (\%) & ${ }^{\circ}$ Brix & AT & Ratio \\
\hline & $48,95 \mathrm{a}$ & $8,25 \mathrm{a}$ & $0,62 \mathrm{a}$ & $13,80 \mathrm{a}$ \\
6. Testemunha & $46,15 \mathrm{a}$ & $7,90 \mathrm{a}$ & $0,61 \mathrm{a}$ & $13,45 \mathrm{a}$ \\
2. Polinização com laranja Natal & $45,45 \mathrm{a}$ & $7,85 \mathrm{a}$ & $0,575 \mathrm{a}$ & $13,30 \mathrm{a}$ \\
3. Polinização com laranja Pêra & $42,30 \mathrm{a}$ & $7,70 \mathrm{a}$ & $0,57 \mathrm{a}$ & $12,95 \mathrm{a}$ \\
1. Polinização com laranja Valência & 4,67 & 9,23 & 8,50 & 6,03 \\
\hline Coeficiente de Variação & &
\end{tabular}

* Médias seguidas de mesma letra na coluna não diferem entre si, ao nível de 5\% de significância, pelo teste de Tukey

ou seja, 9,23 a $11,77^{\circ}$ Brix. Isso ocorreu devido a colheita dos frutos ser realizada um pouco antes da maturação ideal da variedade, em virtude da incidência de Mosca-das-frutas, que, entre outros danos, causa queda dos frutos. Para a análise de ratio, os valores obtidos estão de acordo com os relatados por Pio et al. (1993), sendo entre 11,8 e 15,46.

d) Número médio de sementes por fruto (NMS)

Não houve diferença estatística entre os resultados (Tabela 1). Porém, os valores ficaram acima dos descritos por Pio et al. (1993), para a variedade, em polinização aberta, ou seja, entre 11,33 e 18,39 sementes. Segundo Pio (2006), experimentos realizados em plantio comercial de tangelo Nova, em Taquarivaí-SP, observou-se que, sob condições de isolamento parcial do pomar, $72 \%$ dos frutos apresentaram menos de 5 sementes, e sob isolamento total, $100 \%$ dos frutos não apresentaram sementes (Pio, 2006). Os resultados obtidos evidenciam a influência da polinização cruzada nesta característica do fruto. Influências significativas da polinização cruzada em tangelo Nova também foram observadas por Bono et al. (1989); Soler-Aznar (1999) e Demirkeser et al. (2001).

\section{CONCLUSÕES}

1. O tangelo Nova é uma variedade de polinização altamente compatível com as variedades comerciais de laranjas Pêra, Natal e Valência.

2. Os frutos de tangelo Nova, resultantes da polinização cruzada com essas variedades, apresentaram entre 20 e 23 sementes e não se constataram alterações em suas qualidades organolépticas.

\section{AGRADECIMENTOS}

À FundAg, Fundação de Apoio à Pesquisa Agrícola, pela concessão de bolsa ao primeiro autor e apoio ao projeto.

\section{REFERÊNCIAS}

BONO, R.; CORDOVA, F.; SOLER, J. Behavior of 'Nova' mandarin in Spanish conditions. In: INTERNATIONAL CONGRESS, 6., 1988, Telaviv. Proceedings... v.1, p. 101-106

BONO, R.; O'CONNOR, L. F. C.; AZNAR, J. S. Comportamiento de la mandarina Nova en España. Especial Cítricos. Fruticultura Profesional, Barcelona, n.25, p-29-31, 1989.

CAMERON, J. W.; FROST, H. B. Genetics, breeding and nucellar embriony. In: REUTHER, W.; WEBBER, H. J.; BATCHELOR, L. D. (Ed.). The Citrus industry. Berkeley: California Division of Agricultural Sciences, University of California. 1968. v.2, p.359-360
DAVIES, F. S.; ALBRIGO, L. C. Citrus. Wellingford: Cab International, 1994.245p.

DEMIRKESER, T. H.; ETI, S.; KAPLANKIRAN, M. The effects of self and cross-pollination on the fruit set and quality of Nova mandarin. In: INTERNATIONAL CONGRESS OF CITRUS NURSERYMEN, 6., 2001. Proceedings...Araraquara: EECB/FUNDECITRUS, 2001. p.305-308

BEE Pollination Benefits For Citrus Crops. Western: Departament of Agriculture. Disponível em: <<http://www.agric.wa.gov.au>. Acesso em: 15 dez. 2004

DOORENBOS, J.; KASSAM, A. H. Efeito da água no rendimento das culturas. Campina Grande: UFPB/FAO, 1994. 306p.

FAO- Food and Agriculture Organization. FAOSTAT statistical databases. Disponivel em: <http://apps.fao.org>. Acesso em: 26 jun. 2005

GAYET, J. P. Qualidade de frutas cítricas para exportação. Laranja, Cordeirópolis, v.14, n. 1, p. 87-90, 1993.

GUARDIOLA, J. L. Frutificação e crescimento. In: SEMINARIO INTERNACIONAL DE CÍTRUS, 2., 1992, Bebedouro. Campinas: Fundação Cargill, 1992.

IBGE. Produção agrícola municipal: culturas temporárias e permanentes. Disponível em: 〈http://www.ibge.gov.br>. Acesso em: 12 jan. 2006.

PIO, R. M.; FIGUEIREDO, J. O.; SOBRINHO, J. T.; POMPEU JUNIOR, J. Características do fruto de oito cultivares de tangerineiras e seus híbridos. Revista Brasileira de Fruticultura, Cruz das Almas, v.15, n.1, p.43-47, 1993.

PIO, R. M. Tangerinas para o verão. Laranja, Cordeirópolis, v.14, n.2, p.539-549, 2003.

PIO, R. M.; FIGUEIREDO, J. O.; STUCHI, E. S.; CARDOSO, S. A. B.Variedades de Copas de Citros. In: MATTOS JUNIOR, D.; PIO, R.M.; DE NEGRI, J. D.; POMPEU JUNIOR, J. (Ed.). Citros. Campinas: Instituto Agronômico e FUNDAG, 2005. 929p.

REED, J.B.; HENDRIX, JR., C. M.; HENDRIX, D.L. Quality control manual for citrus processing plants: book I. Safety Harbor: Intercit, 1986. p.169-172

REUTHER, W. Climate and citrus behavior. In: REUTHER, W. (Ed.). The citrus industry. Riverside: UCA Press, 1973. p. 280-337

SAUNT, J. Citrus varieties of the world. Norwich, England: Sinclair International, 1990. p.60-62

SOCIAS, R. La polinizacion de los frutales. Hojas Divulgadoras, Zaragoza, n.17, p.3-18, 1987.

SOLER-AZNAR, J. S. Reconocimiento de variedades de cítricos em campo. Valência: Generalitat Valenciana, 1999. 187p.

Pio, R. M. Comunicação Pessoal 